\title{
ISMAR: an airborne submillimetre radiometer
}

\author{
Stuart Fox ${ }^{1}$, Clare Lee ${ }^{1}$, Brian Moyna ${ }^{2}$, Martin Philipp ${ }^{3}$, Ian Rule ${ }^{1}$, Stuart Rogers ${ }^{1}$, Robert King ${ }^{1}$, \\ Matthew Oldfield ${ }^{2}$, Simon Rea ${ }^{2}$, Manju Henry ${ }^{2}$, Hui Wang ${ }^{2}$, and R. Chawn Harlow ${ }^{1}$ \\ ${ }^{1}$ Met Office, FitzRoy Road, Exeter, EX1 3PB, UK \\ ${ }^{2}$ Rutherford Appleton Laboratory, Harwell Campus, Didcot, OX11 0QX, UK \\ ${ }^{3}$ RPG Radiometer Physics GmbH, Werner-von-Siemens-Str. 4, 53340 Meckenheim, Germany
}

Correspondence to: Stuart Fox (stuart.fox@metoffice.gov.uk)

Received: 21 September 2016 - Discussion started: 27 September 2016

Revised: 9 January 2017 - Accepted: 9 January 2017 - Published: 8 February 2017

\begin{abstract}
The International Submillimetre Airborne Radiometer (ISMAR) has been developed as an airborne demonstrator for the Ice Cloud Imager (ICI) that will be launched on board the next generation of European polarorbiting weather satellites in the 2020s. It currently has 15 channels at frequencies between 118 and $664 \mathrm{GHz}$ which are sensitive to scattering by cloud ice, and additional channels at $874 \mathrm{GHz}$ are being developed. This paper presents an overview of ISMAR and describes the algorithms used for calibration. The main sources of bias in the measurements are evaluated, as well as the radiometric sensitivity in different measurement scenarios. It is shown that for downward views from high altitude, representative of a satellite viewing geometry, the bias in most channels is less than $\pm 1 \mathrm{~K}$ and the NE $\Delta T$ is less than $2 \mathrm{~K}$, with many channels having an NE $\Delta T$ less than $1 \mathrm{~K}$. In-flight calibration accuracy is also evaluated by comparison of high-altitude zenith views with radiative-transfer simulations.
\end{abstract}

\section{Introduction}

ISMAR (International Submillimetre Airborne Radiometer) is a new airborne passive remote-sensing instrument which has been jointly funded by the Met Office and the European Space Agency (ESA). It first flew in 2014 and contains a number of heterodyne receivers operating at frequencies between 118 and $664 \mathrm{GHz}$. The instrument has a modular design allowing additional channels to be added, and receivers at $874 \mathrm{GHz}$ are being developed by Omnisys. The current receiver front ends were designed and built by Rutherford Appleton Laboratory (RAL) Space and Radiometer Physics
$\mathrm{GmbH}$ (RPG), and the intermediate-frequency (IF) back ends were built by Thales Alenia Space. The rest of the instrument design, build and aircraft installation were carried out by RAL, the Met Office, Cranfield Aerospace and BAE Systems.

Previous theoretical studies (e.g. Evans and Stephens, 1995; Evans et al., 1998; Buehler et al., 2007; Jiménez et al., 2007) have suggested that passive submillimetre radiometers can be used for satellite retrievals of ice cloud properties including ice water path, particle size and cloud altitude, which have an important impact on weather and climate prediction (see, for example, Waliser et al., 2009). Submillimetre observations have also been suggested for precipitation retrieval, e.g. the Geostationary Microwave Observatory (GEM; Staelin et al., 1998) and Geostationary Observatory for Microwave Atmospheric Sounding (GOMAS; Bizzari et al., 2005) satellite proposals, and near-source characterisation of volcanic ash plumes (Baran, 2012). Although there are a number of existing satellite submillimetre instruments for Earth observation, e.g. the Earth Observing System (EOS) Microwave Limb Sounder (MLS) on the Aura satellite (Waters et al., 2006) and the Odin submillimetre radiometer (Murtagh et al., 2002), they are primarily designed for measuring atmospheric composition and use a limb-sounding geometry, which gives poor horizontal resolution and restricts measurements to the upper troposphere and above. The channel frequencies are also not optimised for cloud ice retrieval. The Ice Cloud Imager (ICI), due to be launched on board the MetOp second-generation satellites in the 2020s (Kangas et al., 2012), will be the first satellite submillimetre radiometer specifically designed for measuring cloud ice. Its conical scan with a $53^{\circ}$ incidence angle will provide daily global cov- 

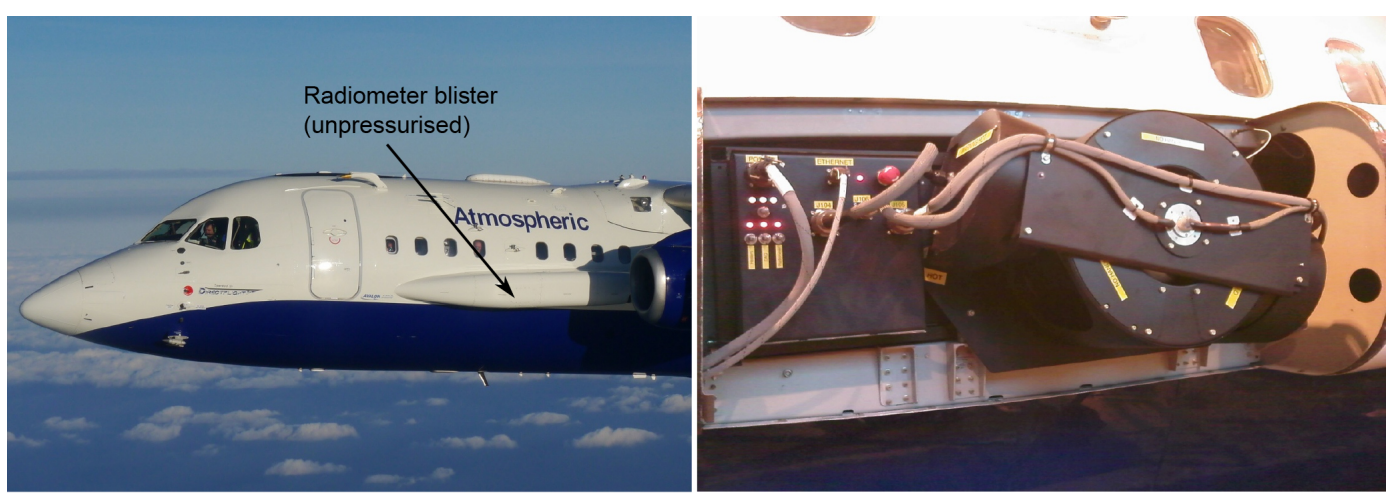

Figure 1. The location of the radiometer blister on the FAAM BAe-146 aircraft, and the ISMAR instrument installed in the blister with the cover removed.

erage of cloud ice properties at $16 \mathrm{~km}$ resolution. Airborne submillimetre observations of ice cloud that can be used to develop and validate retrieval algorithms prior to the launch of ICI are currently rather limited. The Compact Scanning Submillimeter-wave Imaging Radiometer (CoSSIR) instrument on board the NASA ER-2 aircraft has made measurements at 183, 220, 380, 640 and $874 \mathrm{GHz}$ during two tropical campaigns (Evans et al., 2005, 2012), and a single cirrus case study has been observed with the Far-Infrared Sensor for Cirrus (FIRSC) Fourier transform spectrometer on board the Proteus high-altitude aircraft, which has a detector covering approximately $300-1000 \mathrm{GHz}$ (Lee et al., 2002). Observations of Arctic cirrus up to $340 \mathrm{GHz}$ have also been made using the Millimeter-wave Imaging Radiometer (MIR) instrument on the NASA ER-2 (Wang et al., 2001). ISMAR has been developed specifically as an airborne demonstrator for ICI. It has a very similar channel set to ICI and can be used for developing retrieval algorithms as well as for scientific case studies and calibration/validation post-launch.

ISMAR has been certified to fly on the FAAM BAe146 Atmospheric Research Aircraft, which carries complementary instruments measuring basic atmospheric parameters, microwave radiometers, infrared and visible spectrometers, a downward-pointing backscatter lidar and in situ cloud physics probes. Dropsondes can be used to obtain profiles of temperature, humidity and wind below the aircraft.

This paper gives an overview of the design and performance of ISMAR and is arranged as follows: Sect. 2 describes the instrument design, and Sect. 3 describes the methods used to process the data. Section 4 considers the sources of systematic error (bias) in the ISMAR measurements, and Sect. 5 discusses the radiometric sensitivity. In-flight performance is evaluated in Sect. 6 by comparing high-altitude zenith views with radiative-transfer simulations, and conclusions are given in Sect. 7

\section{Instrument design}

ISMAR has a self-contained design, with the receivers, calibration targets, scan mechanism and control electronics contained in a single package with dimensions of approximately $1.1 \times 0.4 \times 0.5 \mathrm{~m}$ and a weight of around $90 \mathrm{~kg}$. An ethernet port allows an operator to monitor and control the instrument during flight. The instrument is installed in the radiometer blister on the front port side of the FAAM BAe-146, allowing unobstructed upward and downward views (Fig. 1), and in future it could also be flown on other high-altitude aircraft.

ISMAR currently has seven uncooled heterodyne receivers providing 15 channels. These are centred on the oxygen absorption line at $118.75 \mathrm{GHz}$ (five channels), the watervapour absorption lines at 325.15 and $448 \mathrm{GHz}$ (three channels each), and atmospheric quasi-windows at 243.2 and $664 \mathrm{GHz}$. All the channels have dual sidebands. The window channels each have two receivers to measure dual polarisations, which gives information about ice particle shape and alignment (Evans et al., 1998). ISMAR has a modular design that allows additional channels to be added as they become available. Further quasi-window receivers at $874.4 \mathrm{GHz}$ are currently being developed, which will give greater sensitivity to small ice particles, and a receiver centred on the $424.7 \mathrm{GHz}$ oxygen absorption line is also planned. A full overview of the ISMAR channel parameters is given in Table 1 . In addition to ISMAR, receivers centred at 23.8, 50.1, 89,157 and $183 \mathrm{GHz}$ are provided by the Deimos (Hewison, 1995) and Microwave Airborne Radiometer Scanning System (MARSS) (McGrath and Hewison, 2001) microwave radiometers on board the aircraft. Together these instruments give a close match to the ICI channels and contain a significant subset of the proposed GOMAS channels.

A schematic of ISMAR is shown in Fig. 2. The front end contains an array of receivers directly viewing a rotating gold-coated planar scan mirror angled at $45^{\circ}$ which directs their field of view on to one of two internal black-body calibration targets or the external scenes. The calibration targets and scan mirror are sized to ensure there is no main-beam 

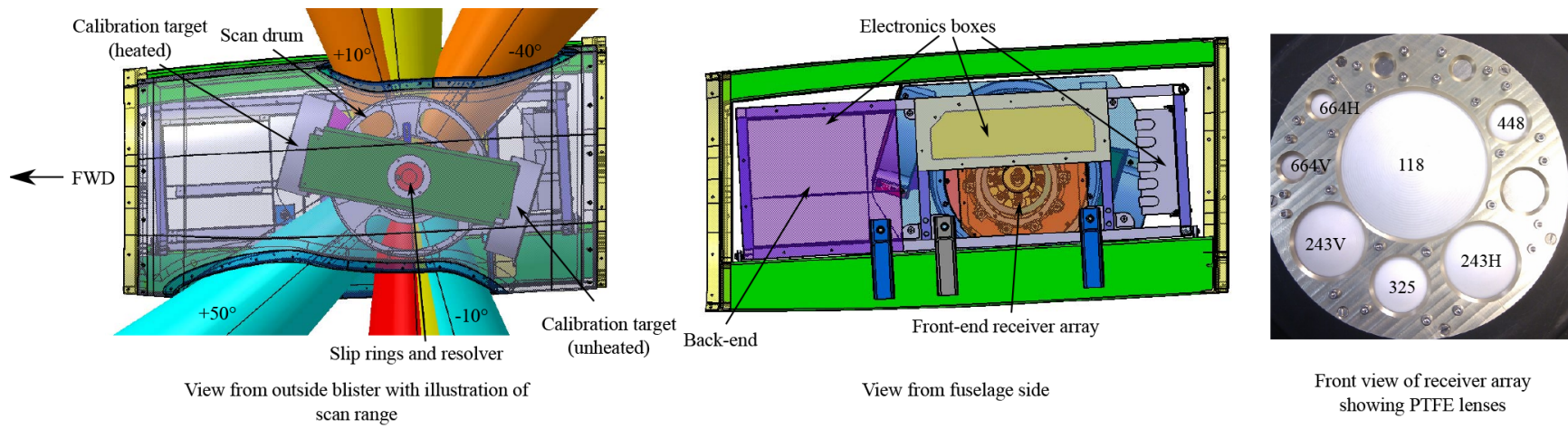

Figure 2. Schematic of ISMAR with illustration of scan range, and image showing the front-end receiver array.

spillover, and the gold coating on the mirror has a thickness of $5 \mu \mathrm{m}$, which is larger than the penetration depth of the radiation at the ISMAR frequencies. The scan mirror is heated to prevent frosting or condensation during flight. The direct-view design eliminates losses due to traditional quasioptical components but requires a larger scan mirror and calibration targets. To save space, the front end is housed inside the frameless scan motor. The scan direction is alongtrack, with nadir views between a nominal +50 and $-10^{\circ}$ and zenith views between +10 and $-40^{\circ}$, where positive scan angles are associated with views in the forward direction as illustrated in Fig. 2. The true scan angles can vary from the nominal angles by a few degrees due to the mounting angle of the instrument on the aircraft and changes in aircraft pitch during flight. The scan pattern is fully configurable through software. A typical scan pattern taking approximately $4 \mathrm{~s}$ will start at the forward (heated) calibration target and step through seven nadir views, the aft (unheated) calibration target and six zenith views.

The design of the scanning mechanism means that the polarisation detected by each receiver varies with scan angle and aircraft attitude. The polarisations are selected such that the single-polarisation channels detect vertical polarisation and the dual-polarisation channels detect horizontal and vertical polarisation when the instrument is viewing the $+50^{\circ}$ nadir direction during straight and level flight. This gives the closest match to the conical scanning geometry of ICI.

Each of the ISMAR receivers has a similar design, and the radio frequency (RF) design schematic is shown in Fig. 3. The receiver front ends consist of near-Gaussian-profiled corrugated horns, having main beams with first side lobes typically at $-35 \mathrm{~dB}$, feeding sub-harmonic planar diode mixers. PTFE lenses, blazed to reduce reflections at each frequency, are used to reduce the half-power beam width (HPBW) for all channels to less than $4^{\circ}$. The antenna response for each receiver has been measured, and the HPBW values are given in Table 1 . The local oscillator (LO) source consists of either a free-running Gunn oscillator or a dielectric resonance oscillator (DRO), followed in either case by a chain of active- and/or passive-frequency multipliers. A $3 \mathrm{~dB}$ waveguide power splitter is used to provide LO power to both of the $243 \mathrm{GHz}$ receivers from a single oscillator. The sub-harmonic mixers and frequency multipliers use European GaAs Schottky diode technology. Commercial off-theshelf (COTS) IF pre-amplifiers are used to boost the signals before they are passed to the IF back ends. The back ends are built from COTS components and consist of a power amplifier, power divider $(118,325$ and $448 \mathrm{GHz}$ only), discretecomponent or cavity bandpass filters and tunnel diode detectors. The voltage output from each detector passes through a custom-designed two-stage linear amplifier circuit where a precision voltage offset is applied to ensure the signal remains within the range of the A/D converter. The amplifier also acts as a low-pass filter with a cut-off frequency of $1 \mathrm{kHz}$ to provide the first stage of signal integration. The output from the amplifier is then digitally sampled and further integrated using a National Instruments CompactRIO embedded controller. The sampling rate and overall integration time are software configurable with a typical total integration period of $100 \mathrm{~ms}$.

The performance of the ISMAR receivers has been comprehensively characterised, including measurements of system noise temperature and channel passband shape (see Table 1). The sideband imbalance has also been measured by using a Martin-Puplett interferometer to create a singlesideband filter, allowing the receiver upper and lower sidebands to be independently exposed to ambient and cold targets. The imbalance was less than $\pm 1 \mathrm{~dB}$ for all receivers, which is the estimated accuracy of the measurement. Since the gaseous absorption lines where the channels are centred are symmetrical and cloud-ice scattering signals are expected to vary slowly with frequency, a $1 \mathrm{~dB}$ imbalance will not have a significant impact.

The gain of the ISMAR receivers is temperaturedependent, so active thermal control is used to maintain a constant temperature. Frequent in-flight views of the two black-body calibration targets (designed and built by RAL) are also used to provide continuous calibration. One of the targets is actively heated to $353 \mathrm{~K}$ using a printed circuit heater element laminated to the back of the target sub- 
Table 1. ISMAR channel definitions (including planned upgrades).

\begin{tabular}{|c|c|c|c|c|c|c|c|}
\hline $\begin{array}{l}\text { Centre } \\
\text { frequency } \\
(\mathrm{GHz})\end{array}$ & $\begin{array}{l}\text { Frequency } \\
\text { offset } \\
(\mathrm{GHz})\end{array}$ & $\begin{array}{l}\text { IF bandwidth } \\
(\mathrm{GHz})\end{array}$ & $\begin{array}{l}\text { Polarisation } \\
\text { (at }+50^{\circ} \\
\text { downward view) }\end{array}$ & Feature & $\begin{array}{l}\text { System noise } \\
\text { temperature } \\
(\mathrm{K})\end{array}$ & $\begin{array}{l}\text { Beamwidth } \\
\text { E-/H-plane } \\
\left({ }^{\circ} \mathrm{FWHM}\right)\end{array}$ & $\begin{array}{l}\text { In-band ripple } \\
\text { ( } 90 \% \text { bandwidth) } \\
\text { (dB) }\end{array}$ \\
\hline 118.75 & $\begin{array}{l} \pm 1.1 \\
\pm 1.5 \\
\pm 2.1 \\
\pm 3.0 \\
\pm 5.0\end{array}$ & $\begin{array}{l}0.4 \\
0.4 \\
0.8 \\
1.0 \\
2.0\end{array}$ & $\mathrm{~V}$ & $\mathrm{O}_{2}$ & $\begin{array}{l}<700 \\
<700 \\
<700 \\
<700 \\
690\end{array}$ & $3.37 / 3.79$ & $\begin{array}{l} \pm 1.35 \\
\pm 1.05 \\
\pm 1.4 \\
\pm 2.0 \\
\pm 1.8\end{array}$ \\
\hline 243.2 & \pm 2.5 & 3.0 & $\mathrm{~V} \& \mathrm{H}$ & Window & $\begin{array}{l}1850(\mathrm{~V}) \\
1700(\mathrm{H})\end{array}$ & $\begin{array}{l}3.52 / 3.42(\mathrm{~V}) \\
3.54 / 3.45(\mathrm{H})\end{array}$ & $\begin{array}{l} \pm 1.75 \\
\pm 1.15\end{array}$ \\
\hline 325.15 & $\begin{array}{l} \pm 1.5 \\
\pm 3.5 \\
\pm 9.5\end{array}$ & $\begin{array}{l}1.6 \\
2.4 \\
3.0\end{array}$ & $\mathrm{~V}$ & $\mathrm{H}_{2} \mathrm{O}$ & $\begin{array}{l}2138 \\
2085 \\
2042\end{array}$ & $3.38 / 3.52$ & Not available \\
\hline 424.7 & $\begin{array}{l} \pm 1.0 \\
\pm 1.5 \\
\pm 4.0\end{array}$ & $\begin{array}{l}0.4 \\
0.6 \\
1.0\end{array}$ & $\mathrm{~V}$ & $\mathrm{O}_{2}$ & Optional upgrade & & \\
\hline 448.0 & $\begin{array}{l} \pm 1.4 \\
\pm 3.0 \\
\pm 7.2\end{array}$ & $\begin{array}{l}1.2 \\
2.0 \\
3.0\end{array}$ & $\mathrm{~V}$ & $\mathrm{H}_{2} \mathrm{O}$ & $\begin{array}{l}2500 \\
3000 \\
3500\end{array}$ & $3.35 / 3.53$ & $\begin{array}{l} \pm 1.15 \\
\pm 2.0 \\
\pm 1.35\end{array}$ \\
\hline 664.0 & \pm 4.2 & 5.0 & $\mathrm{~V} \& \mathrm{H}$ & Window & $\begin{array}{l}2500(\mathrm{~V}) \\
2000(\mathrm{H})\end{array}$ & $\begin{array}{l}3.66 / 3.72(\mathrm{~V}) \\
3.59 / 3.70(\mathrm{H})\end{array}$ & $\begin{array}{l} \pm 3.8 \\
\pm 3.15\end{array}$ \\
\hline 874.4 & \pm 6.0 & 3.0 & $\mathrm{~V} \& \mathrm{H}$ & Window & Under development & & \\
\hline
\end{tabular}

strate, whilst the other is allowed to drift, typically being slightly warmer than the ambient temperature due to the thermal conditions inside the radiometer blister. The calibration targets are based on prototype designs developed for the ALMA telescope and consist of pyramidal structures with base $10 \mathrm{~mm}$ and height $40 \mathrm{~mm}$ coated with Eccosorb CR-114 absorber. The substrate is machined from magnesium alloy to save weight. The measurements of Murk et al. (2008) indicate that the monostatic return loss from the calibration targets should be greater than $50 \mathrm{~dB}$ at ISMAR frequencies. Target temperatures are monitored by up to 10 Minco type S9688PA1X12 platinum resistance thermometers (PRTs) embedded in the target substrates. These PRTs are at a depth of $30 \mathrm{~mm}$ from the rear face of the target and $20 \mathrm{~mm}$ from the tips of the pyramids. Additional PRTs located at depths of 15 and $50 \mathrm{~mm}$ from the rear face of the target can be used to monitor thermal gradients within the substrate (see Fig. 4). The target PRTs have been individually calibrated against a traceable standard. During flight the calibration targets experience significant airflow, so in order to reduce the rate of heat loss and thermal gradients within the heated target it is protected by a $8 \mu \mathrm{m}$ polypropylene window stretched over the front of the target. Flight tests showed that without the window the hot target temperature cannot be maintained at $353 \mathrm{~K}$ and temperature variability across the target is substantially increased. A correction for the inser- tion loss of the window is included in the calibration processing as discussed in Sect. 4.2.

\section{Calibration and processing}

This section describes the calibration procedure used to derive scene brightness temperatures from the receiver voltages. Each ISMAR channel is assumed to output a voltage $V_{\text {scene }}$ that varies linearly with received power from the scene, $P_{\text {scene }}$, according to

$P_{\text {scene }}=\frac{V_{\text {scene }}}{G}-P_{\text {rec }}$.

The linear gain, $G$ and offset $P_{\text {rec }}$ are calculated using the calibration target views by

$$
\begin{gathered}
G=\frac{\overline{V_{\text {hot }}}-\overline{V_{\text {cold }}}}{\overline{P_{\text {hot }}}-\overline{P_{\text {cold }}}} \\
P_{\text {rec }}=\frac{\overline{V_{\text {cold }}}}{G}-\overline{P_{\text {cold }}} .
\end{gathered}
$$

The overbar represents the uniformly weighted mean value for all calibration views within a $60 \mathrm{~s}$ window centred on the time of the scene view. This time window has been selected to minimise the noise in the measured brightness temperatures (see Sect. 5). The received powers from the hot and 


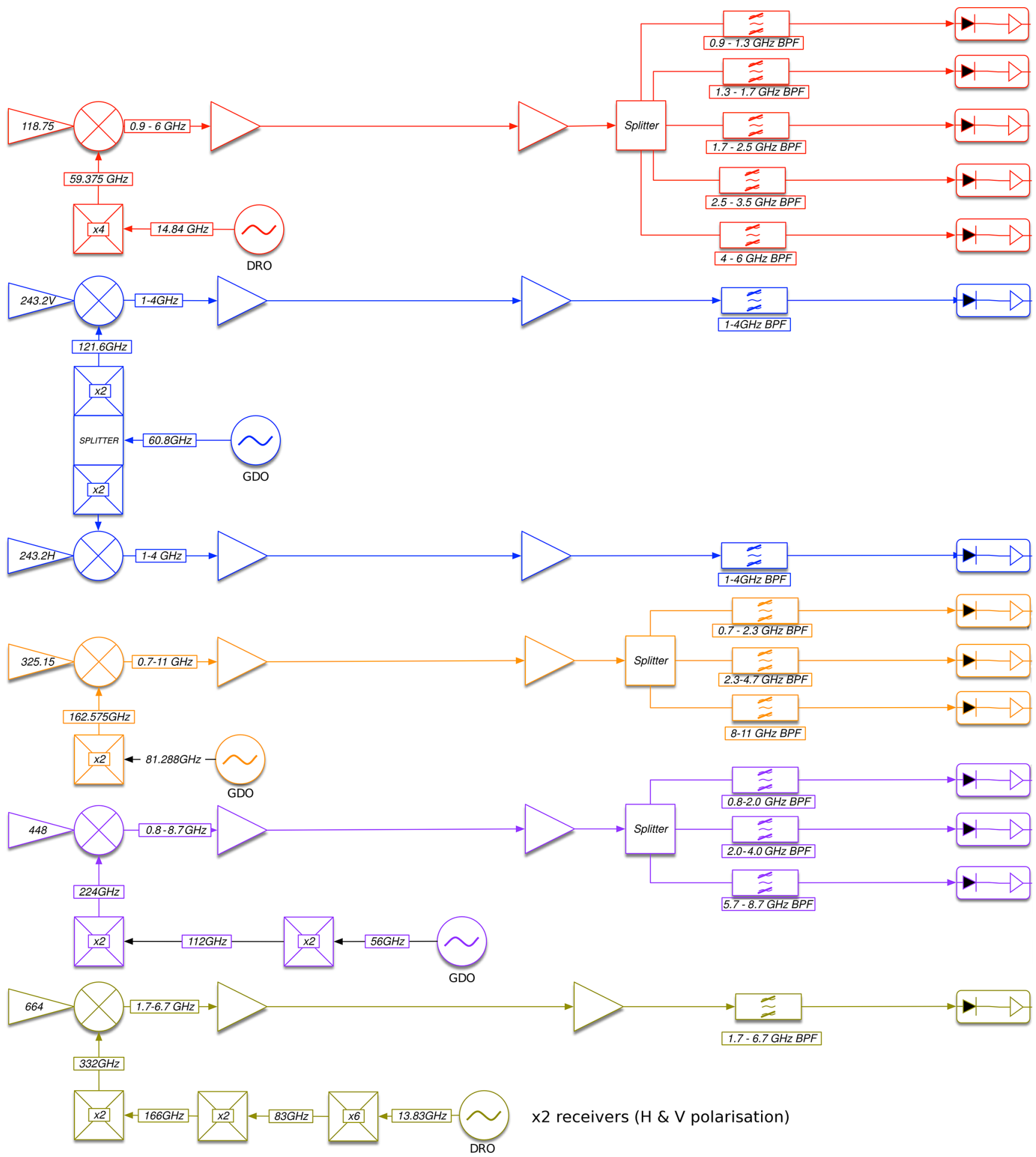

Figure 3. Schematic of the ISMAR RF design.

cold calibration targets are calculated from the target temperatures as described below. Deviations in the receiver output from the linear response Eq. (1) will give errors in calibrated brightness temperature, and a correction is required for some ISMAR channels as described in Sect. 4.5.

It is common when calibrating microwave radiometers to assume that the received power from a black body is linearly 

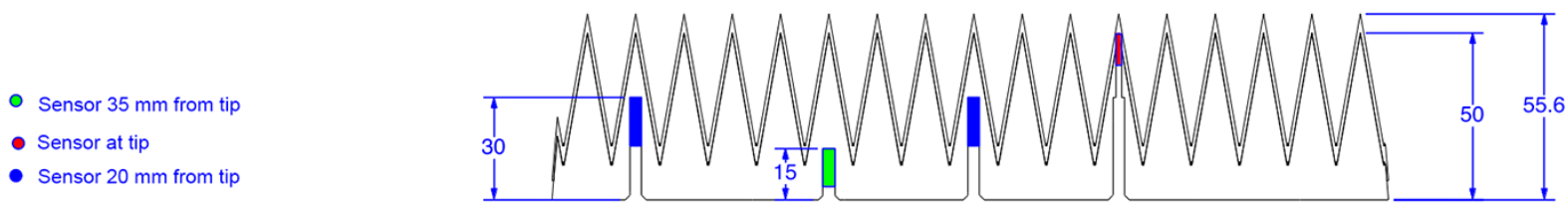

Figure 4. Cross section of internal calibration target showing locations of PRTs.

related to its temperature, allowing temperatures to be used in place of received power in the above equations (see the discussion in Han and Westwater, 2000, for example). Equation (1) then gives a direct measurement of the scene brightness temperature. However, at the largest frequencies used by ISMAR the linear assumption is no longer valid, and a more accurate approximation is required as described below.

The power received by a radiometer when viewing a black body at temperature $T$ is given by

$P=\int \frac{h v}{\exp ^{h v / k T}-1} W(v) \mathrm{d} v$,

where $h$ is Plank's constant; $k$ is Boltzmann's constant; $v$ is frequency; and $W(v)$ is the channel passband shape which, for a dual-sideband receiver, includes both of the sidebands and any sideband imbalance. Equation (4) can be obtained by integrating Eq. (1.17) from Jones (1995), weighted according to the channel passband shape. For ISMAR calibration a suitably accurate approximation to Eq. (4) can be made by assuming that the integrand in Eq. (4) varies linearly across each of the channel sidebands and that there is no sideband imbalance. This gives

$P \approx\left(\frac{h v_{\text {low }}}{\exp ^{h v_{\text {low }} / k T}-1}+\frac{h v_{\text {hi }}}{\exp ^{h v_{\text {hi }} / k T}-1}\right) \Delta v$,

where $v_{\text {low }}$ and $v_{\text {hi }}$ are the centre frequencies of the two channel sidebands and $\Delta v$ is the channel IF filter bandwidth. Note that this approximation is appropriate for the black-body calibration targets where the received power varies slowly and smoothly as a function of frequency. However, when calculating received scene power from radiative-transfer models where there may be sharp variations due to spectral lines, it may be necessary to use Eq. (4) directly, depending on the accuracy required. For ISMAR calibration Eq. (5) is used to calculate the received powers from the hot and cold calibration targets that are required to estimate the receiver gain and offset.

The ISMAR measurements of received scene power are converted to a channel-average Rayleigh-Jeans equivalent brightness temperature defined by

$T_{\text {scene,rje }}=\frac{P_{\text {scene }}}{k \int W(v) \mathrm{d} v}$,

where the approximation in Eq. (5) implies that $\int W(v) \mathrm{d} v=$ $2 \Delta v$.
As discussed by McGrath and Hewison (2001), non-unity reflectivity $\Gamma$ of the scan mirror results in contamination of the observed power for both scene and target views:

$\Delta P=(1-\Gamma)\left(P_{\text {mirror }}-P\right)$.

In the case of a constant-temperature mirror with a constant reflectivity this contamination will be accounted for during the standard calibration process. However, the mirror temperature may not be constant, and the reflectivity varies as the detected polarisation relative to the mirror changes through the scan. A theoretical calculation for a plane mirror angled at $45^{\circ}$ assuming a bulk conductivity of gold of $4.1 \times 10^{7} \Omega^{-1} \mathrm{~m}^{-1}$ gives reflectivities for parallel and perpendicular polarisations of 0.9984 and 0.9992 respectively at $118 \mathrm{GHz}$, reducing to 0.9957 and 0.9978 at $874 \mathrm{GHz}$. For a constant-temperature mirror at $240 \mathrm{~K}$ viewing a scene with a brightness temperature of $10 \mathrm{~K}$ this can lead to a change in power correction with scan angle equivalent to a brightness temperature change of up to $0.48 \mathrm{~K}$. Equation (7) is therefore used to correct all calibration target and scene views, with $P_{\text {mirror }}$ calculated from Eq. (5) using the measured mirror temperature.

The polypropylene window in front of the heated target can also contaminate the observed power during calibration views. A correction for reflection from the window is included in the calibration processing as described in Sect 4.2.

\section{Calibration biases}

This section considers the main sources of bias in the ISMAR measurements. Here we consider a bias to be an error in scene temperature that varies slowly, typically over timescales of minutes or more, and generally in response to changes in the ambient environment. The main sources of bias are errors in the calibration target temperature estimates (Sect. 4.1), losses introduced by the window in front of the hot target (Sect. 4.2) and coherent backscatter of leaked local oscillator power from the calibration target leading to standing waves (Sect. 4.3). Some of the ISMAR receivers also have a slightly non-linear response as discussed in Sect. 4.5. Where possible corrections are applied to reduce measurement biases, and estimates are made of the residual uncertainty. 

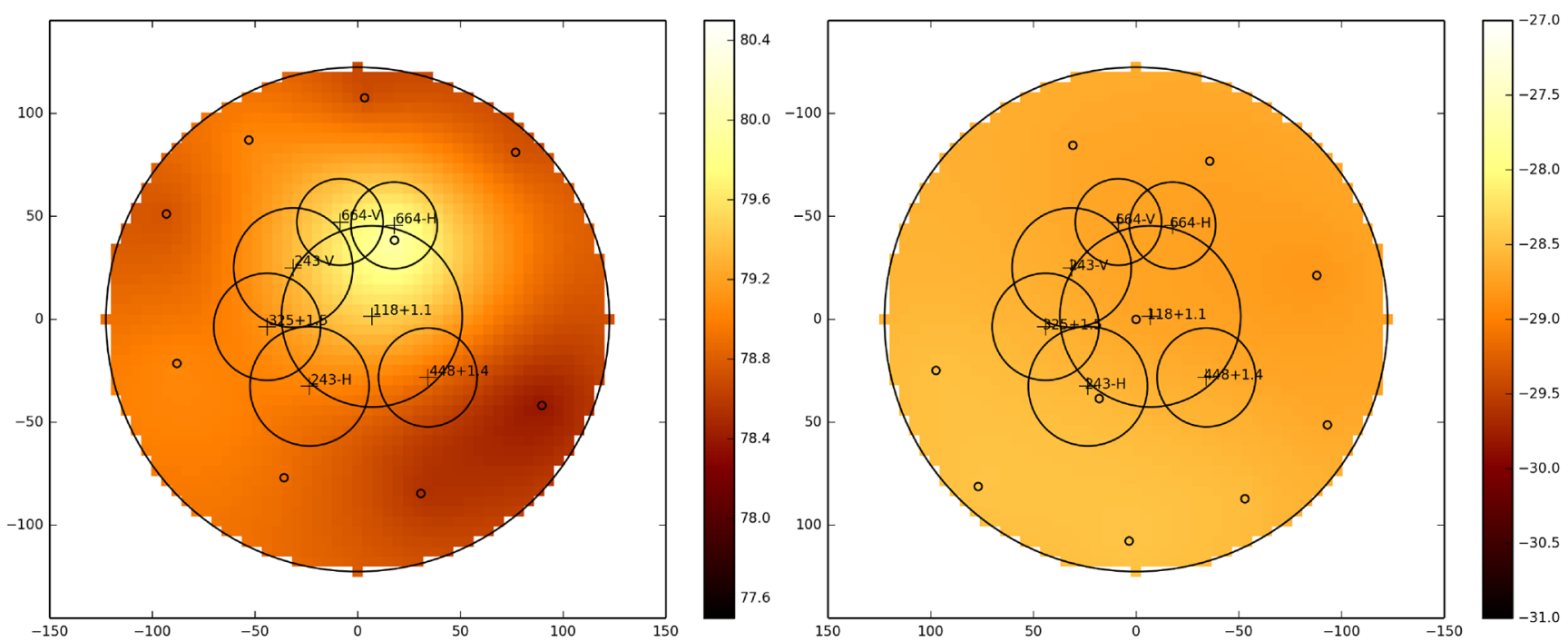

Figure 5. Hot (left) and ambient (right) calibration target temperature distribution during high-altitude flight. The small circles represent the locations of the PRTs, and the colour shows the temperature (in ${ }^{\circ} \mathrm{C}$ ) obtained by interpolating between the measurements. The $-3 \mathrm{~dB}$ footprint of the receivers is also indicated by the larger circles.

\subsection{Calibration target temperatures}

Errors in the radiometric temperature of the internal calibration targets lead directly to errors in the target power and hence the measured antenna temperatures. The temperature required to calculate the target power for each receiver in Eq. (5) is the area average of the absorber surface temperature weighted according to the antenna response pattern. This must be estimated from the measurements made by the PRTs embedded in the substrate of the target. Errors in calibration target temperature arise from a number of sources, including errors in the PRT calibrations, and thermal gradients within the targets, both across the target and between the target substrate where the PRTs are located and the surface of the absorber.

The error in scene brightness temperature $\delta T_{\text {scene,rje }}=$ $T_{\text {scene, measured }}-T_{\text {scene,true }}$ caused by errors in hot and cold target temperatures $\delta T_{\text {hot }}$ and $\delta T_{\text {cold }}$ is approximated by

$\delta T_{\text {scene, }, \text { re }} \approx K \delta T_{\text {hot }}+(1-K) \delta T_{\text {cold }}$,

where $K$ is the calibration interpolation/extrapolation factor given by

$K=\frac{T_{\text {scene,rje }}-T_{\text {cold,rje }}}{T_{\text {hot,rje }}-T_{\text {cold,rje }}}$.

Note that Eq. (8) relies on the approximation $\mathrm{d} T_{\text {rje }} / \mathrm{d} T \approx 1$ being valid at the calibration target temperatures. At $874 \mathrm{GHz}$ and $200 \mathrm{~K}, \mathrm{~d} T_{\text {rje }} / \mathrm{d} T=0.996$, so the errors introduced by this approximation are small. The impact of calibration target temperature errors on the scene brightness temperature error depends on both the scene brightness temperature and the calibration target temperatures. It is greatest when viewing very cold scenes which lie outside the range of the calibration target temperatures, e.g. for zenith views in window channels, and when the temperature difference between the calibration targets temperatures is small. Note that although the biases for zenith views are expected to be larger than for nadir views (as they will often be significantly colder than either calibration target) they are also less critical to the primary purpose of ISMAR as a demonstrator for ICI where the nadir views are more relevant. For a typical mid-latitude winter flight the ambient target temperature varies between $285 \mathrm{~K}$ at low altitude and $245 \mathrm{~K}$ at high altitude, and the heated target temperature is $353 \mathrm{~K}$, leading to values of $K$ ranging from -1 to 0.25 for nadir views and -3 to 0 for zenith views.

The individual target PRTs were calibrated against a traceable standard using the Met Office calibration facility. The resistance of each PRT was measured at temperatures between 223 and $323 \mathrm{~K}$, and a quadratic regression between temperature and resistance was performed. The maximum difference between the quadratic fit and the measured temperature was $0.03 \mathrm{~K}$, with many of the PRTs having a maximum error of $0.01 \mathrm{~K}$. The bias due to PRT calibration error will therefore be small and can be neglected.

We now consider how to estimate the target temperature over the receiver footprints from the PRT measurements. An indication of thermal gradients across the calibration target is given by the difference in the temperatures measured by the PRTs in different locations. The left-hand plot in Fig. 5 shows the temperatures measured by the PRTs in the heated calibration target during a time when the aircraft is level at $32000 \mathrm{ft}$. The small circles indicate the locations of the 
Table 2. Maximum typical calibration target temperature bias estimates and associated scene temperature biases during high-altitude flight.

\begin{tabular}{lrrrrrrrr}
\hline Receiver & $\delta T_{\text {hot }}(\mathrm{K})$ & $\delta T_{\text {cold }}(\mathrm{K})$ & $\delta T_{\text {hot }}(\mathrm{K})$ & $\delta T_{\text {hot }}(\mathrm{K})$ & $\begin{array}{r}\delta T_{\text {hot }}(\mathrm{K}) \\
\text { Gradients }\end{array}$ & $\begin{array}{r}\delta T_{\text {cold }}(\mathrm{K}) \\
\text { Gradients }\end{array}$ & $\begin{array}{r}\delta T_{\text {scene,rje }}(\mathrm{K}) \\
K=0.25\end{array}$ & $\begin{array}{r}\delta T_{\text {scene,rje }}(\mathrm{K}) \\
K=-2\end{array}$ \\
\hline 118 (except \pm 3.0$)$ & +0.4 & \pm 0.2 & +0.3 & +0.03 & 0.0 & 0.0 & $-0.2-0.3$ & $-2.1-0.6$ \\
$118 \pm 3.0$ & +0.4 & \pm 0.2 & +0.3 & +0.03 & -1.0 & -1.0 & $-1.2-0.3$ & $-5.1-2.6$ \\
$243-\mathrm{H}$ & +0.7 & \pm 0.2 & +0.3 & +0.05 & 0.0 & 0.0 & $-0.2-0.4$ & $-2.7-0.6$ \\
$243-\mathrm{V}$ & +0.5 & \pm 0.2 & +0.3 & +0.05 & 0.0 & 0.0 & $-0.2-0.4$ & $-2.3-0.6$ \\
325 & +0.6 & \pm 0.2 & +0.3 & +0.07 & 0.0 & 0.0 & $-0.2-0.4$ & $-2.5-0.6$ \\
448 & +0.7 & \pm 0.2 & +0.3 & +0.10 & 0.0 & 0.0 & $-0.2-0.4$ & $-2.8-0.6$ \\
$664-\mathrm{H}$ & +0.2 & $-0.2-0.1$ & +0.3 & +0.14 & -1.5 & -1.5 & $-1.7-0.2$ & $-6.4-3.3$ \\
$664-\mathrm{V}$ & +0.3 & $-0.2-0.1$ & +0.3 & +0.14 & -2.0 & -2.0 & $-2.2-0.3$ & $-8.1-4.3$ \\
\hline
\end{tabular}

PRTs, and the colour shows the temperature obtained at each point on the target by interpolating between the measurements. Also shown are the $-3 \mathrm{~dB}$ footprints of the receivers, indicated by the larger circles. The centre of the target is warmer than the edges, with a maximum difference of $1.7 \mathrm{~K}$ between the PRTs. Larger temperature differences (up to $3 \mathrm{~K}$ ) are observed during times when the aircraft is changing altitude. Initially the hot target temperature used for the calibration was derived by weighting the interpolated PRT temperatures according to the antenna footprints. However, it was found that measurement biases with respect to both an external liquid-nitrogen-cooled target and simulations of zenith brightness temperatures at high altitude could be reduced by using the temperature of the most central PRT for all receivers. This can be justified by noting that thermal images of the heated target in the laboratory suggest that the central hotspot is much larger than indicated by the interpolated temperatures shown in Fig. 5, which are influenced by the fact that most of the temperature measurements are made close to the edge of the target. Since the channels all have greatest sensitivity near the centre of the target, the most central PRT gives the best estimate of the temperature seen by the receivers. The maximum (hot) bias in the heated calibration target due to gradients across the target is estimated as half the difference between the central PRT and the antenna-averaged interpolated temperature. Values of the hot-calibration-target temperature bias representative of high-altitude level flight are summarised in Table 2.

The right-hand plot in Fig. 5 shows the temperatures measured by the PRTs in the ambient calibration target when the aircraft is level at 32000 feet. The temperature gradients are much smaller than for the heated target, with a maximum difference of $0.37 \mathrm{~K}$ between the PRTs. Much larger temperature differences (up to $4 \mathrm{~K}$ ) can be observed when the aircraft altitude is changing. Since the target is unheated, the temperature gradients are expected to be relatively uniform across the target, and the antenna-weighted interpolated PRT temperature is used as the best estimate of the ambient target temperature for the calibration. The maximum bias in the ambient target temperature due to gradients across the target is estimated as $\delta T_{\text {cold }}= \pm 0.25\left(T_{\max }-T_{\min }\right)$, where
$T_{\max }$ and $T_{\min }$ are the maximum and minimum temperatures measured by the PRTs. Where necessary the temperature bias estimate is reduced to ensure that $T_{\text {est }}+\delta T_{\text {cold }}<T_{\max }$ and $T_{\text {est }}-\delta T_{\text {cold }}>T_{\min }$. Table 2 gives typical cold-targettemperature biases estimated using this method during highaltitude level flight.

Due to the relatively low thermal conductivity of the Eccosorb absorber, thermal gradients may exist through the thickness of the absorber. Infrared images of the heated target in laboratory conditions show that the tips of the pyramids are significantly cooler than the bulk of the target, but they occupy a very small area and so will have a limited impact on the area-weighted target temperature. Unfortunately the infrared camera is not well calibrated, and the infrared emissivity of the target is not known, so it is not possible to use the images to determine the difference between the surface and PRT temperatures. An order-of-magnitude estimate based on the heater power required to maintain the target in thermal equilibrium, the surface area of the pyramids and the thermal conductivity of the absorber suggests that temperature differences between the substrate and absorber surface of up to $0.3 \mathrm{~K}$ are possible. Due to the large uncertainty in this estimate no correction is applied to the calibration for gradients through the absorber on the hot target, and they are included in the estimate of bias in Table 2. For the ambient target the temperature differences between the substrate and the surface will be negligible when the target is thermally stable during level flight but may be significant during aircraft profiles when the target temperature is changing.

\subsection{Window losses}

An $8 \mu \mathrm{m}$ polypropylene window in front of the heated calibration target is used to protect the target from airflow during flight. This allows the target to be maintained at the correct temperature and reduces thermal gradients across the target. However, there is the potential for absorption/emission and reflection from the window to contaminate the received power during calibration views, leading to measurement biases. The transmission loss of the window at ISMAR frequencies has not been directly measured. However, it is possible to estimate both the absorption/emission and reflec- 
tion as a function of frequency $v$ from the complex relative permittivity $\varepsilon_{\mathrm{W}}$ of the window material. These are given by (Ulaby et al., 1981, 247 pp.)

$$
\begin{gathered}
e_{w}=\frac{\left(1-\Gamma_{1}\right)\left(1-\frac{\Gamma_{1}}{L_{w}^{2}}\right)-\frac{1}{L_{w}}\left(1-\Gamma_{1}\right)^{2}}{\left(1+\frac{\Gamma_{1}^{2}}{L_{w}^{2}}\right)-\frac{2 \Gamma_{1}}{L_{w}} \cos \left(2 \beta_{\mathrm{w}} d\right)}, \\
\Gamma_{w}=\Gamma_{1}\left[\frac{\left(1+\frac{1}{L_{w}^{2}}\right)-\frac{2}{L_{w}} \cos \left(2 \beta_{\mathrm{w}} d\right)}{\left(1+\frac{\Gamma_{1}^{2}}{L_{w}^{2}}\right)-\frac{2 \Gamma_{1}}{L_{w}} \cos \left(2 \beta_{\mathrm{w}} d\right)}\right],
\end{gathered}
$$

where $e_{w}$ is the power absorption/emission coefficient, $\Gamma_{w}$ is the power reflectivity and $d$ is the window thickness. For normal incidence the power loss factor $L_{w}=\exp \left(2 \alpha_{\mathrm{w}} d\right)$, and the Fresnel reflection coefficient $\Gamma_{1}=\mid\left(\sqrt{\varepsilon_{\mathrm{w}}}-1\right) /\left(\sqrt{\varepsilon_{\mathrm{w}}}+\right.$ 1) $\left.\right|^{2} . \alpha_{\mathrm{w}}$ and $\beta_{\mathrm{w}}$ are related to the relative permittivity of the window material by $\alpha_{\mathrm{w}}=2 \pi \nu\left|\Im\left(\sqrt{\varepsilon_{\mathrm{w}}}\right)\right| / c$ and $\beta_{\mathrm{w}}=$ $2 \pi \nu \Re\left(\sqrt{\varepsilon_{\mathrm{w}}}\right) / c$, where $c$ is the speed of light in a vacuum.

The relative permittivity $\varepsilon_{\mathrm{W}}$ of polypropylene at millimetre and submillimetre wavelengths has been measured by a number of authors (Afsar, 1985; Jin et al., 2006; Hejase et al., 2011). The real part is relatively constant at all frequencies with a value between 2.2 and 2.3. The imaginary part is rather small but shows significant variability between the measurements. Afsar (1985) finds a loss tangent $\Im\left(\varepsilon_{\mathrm{W}}\right) / \Re\left(\varepsilon_{\mathrm{w}}\right)$ of around $6 \times 10^{-4}$ up to $300 \mathrm{GHz}$, whilst Hejase et al. (2011) and Jin et al. (2006) measure a loss tangent of 0.002 and 0.008 at $1 \mathrm{THz}$ respectively. For polypropylene the loss tangent may depend strongly on impurities in the material (Afsar, 1985). However, for a thin low-loss material where $L_{w} \approx 1$ the window reflectivity can be estimated using only the real part of the relative permittivity, which we take to have a value of 2.25 . We therefore apply a correction for the reflective loss from the window and treat the absorption and emission as an additional hot-target temperature uncertainty.

The window reflectivity correction to the hot-target power is given by $\Delta P_{\text {hot }}=\Gamma_{w}\left(P_{\text {refl }}-P_{\text {hot }}\right)$, where the reflected power $P_{\text {refl }}$ is assumed to come from thermal emission at the ambient temperature in the blister and is approximated by the cold-target power $P_{\text {cold }}$. The correction is negligible at $118 \mathrm{GHz}$ where $\Gamma_{w}=0.00015$, but at $664 \mathrm{GHz}$ the reflection coefficient $\Gamma_{w}=0.0048$, which for a calibration target temperature difference of $100 \mathrm{~K}$ is equivalent to a $0.48 \mathrm{~K}$ change in hot target temperature.

The absorption and emission from the window are treated as a hot-target temperature uncertainty approximated by $\delta T_{\text {hot }}=e_{w}\left(T_{\text {hot }}-T_{\mathrm{w}}\right)$, where $T_{\mathrm{w}}$ is the window temperature. Worst-case values of a loss tangent of 0.008 and a window temperature equal to the cold target temperature $T_{\mathrm{w}}=T_{\text {cold }}$ are used. Estimated values for the hot-target temperature uncertainty due to the window absorption and emission are given in Table 2 assuming a target temperature separation of $100 \mathrm{~K}$. The uncertainty is relatively small, with a maximum value of $\delta T_{\text {hot }}=0.14 \mathrm{~K}$ for the $664 \mathrm{GHz}$ receivers.

\subsection{Coherent backscatter}

Although the coherent backscatter from the ISMAR calibration targets is expected to be low (Murk et al., 2008, measured less than $-50 \mathrm{~dB}$ for a similar target), there is still the potential for standing waves between the receiver and the target to affect the calibration if sufficient power is radiated from the receiver. Reflection from the window in front of the hot target also has the potential to introduce standing waves. Any standing wave will be sensitive to small changes in instrument geometry such as the distance between the receiver and the target and the angle at which the target is viewed. Measurements of the calibration target brightness temperature during small changes in viewing angle can therefore indicate whether standing waves are an issue.

Measurements of the hot- and cold-calibration-target brightness temperatures for a number of viewing angles close to the nominal target position indicate that standing waves are an issue for several ISMAR receivers. Differences with viewing angle of up to $1,1.5$ and $2 \mathrm{~K}$ are observed for the $118 \pm 3.0 \mathrm{GHz}, 664-\mathrm{H}$ and $664-\mathrm{V}$ receivers respectively, with negligible differences for the other receivers. Similar changes with viewing angle are observed for both the hot and cold targets, indicating that the window in front of the hot target is not contributing significantly to the effect. At $118 \pm 3.0 \mathrm{GHz}$ the source of the standing wave is leaked power at $121.6 \mathrm{GHz}$ from the local oscillators from the $243 \mathrm{GHz}$ receivers, whereas at $664 \mathrm{GHz}$ the source appears to be the receiver itself.

Note that coherent backscatter will always increase the voltage observed when viewing a calibration target at a given temperature; hence it is the equivalent of viewing a target at a higher temperature, i.e. a negative value of $\delta T_{\text {hot }}$ or $\delta T_{\text {cold }}$ in Eq. (8). No corrections are currently applied to account for coherent backscatter because the error is difficult to quantify and may vary through a flight. The maximum target temperature bias estimate for each receiver due to coherent backscatter is given in Table 2.

\subsection{Scene temperature bias}

The worst-case scene temperature biases due to the target temperature biases described in the previous sections are given in Table 2 for $K=0.25$ and -2 , which are representative of nadir and zenith views respectively. For nadir views the scene temperature bias is generally less than $\pm 1 \mathrm{~K}$, the exception being the $664 \mathrm{GHz}$ receivers which are affected by coherent backscatter. The potential biases are larger (up to $2.6 \mathrm{~K}$ for receivers not affected by coherent backscatter) for zenith views as the target temperature errors are amplified by the extrapolation from the target temperatures to the low scene temperatures. In the future it may be possible to reduce measurement biases through better characterisation of the calibration target temperatures, and by changing the design of the calibration targets to reduce coherent backscatter. 

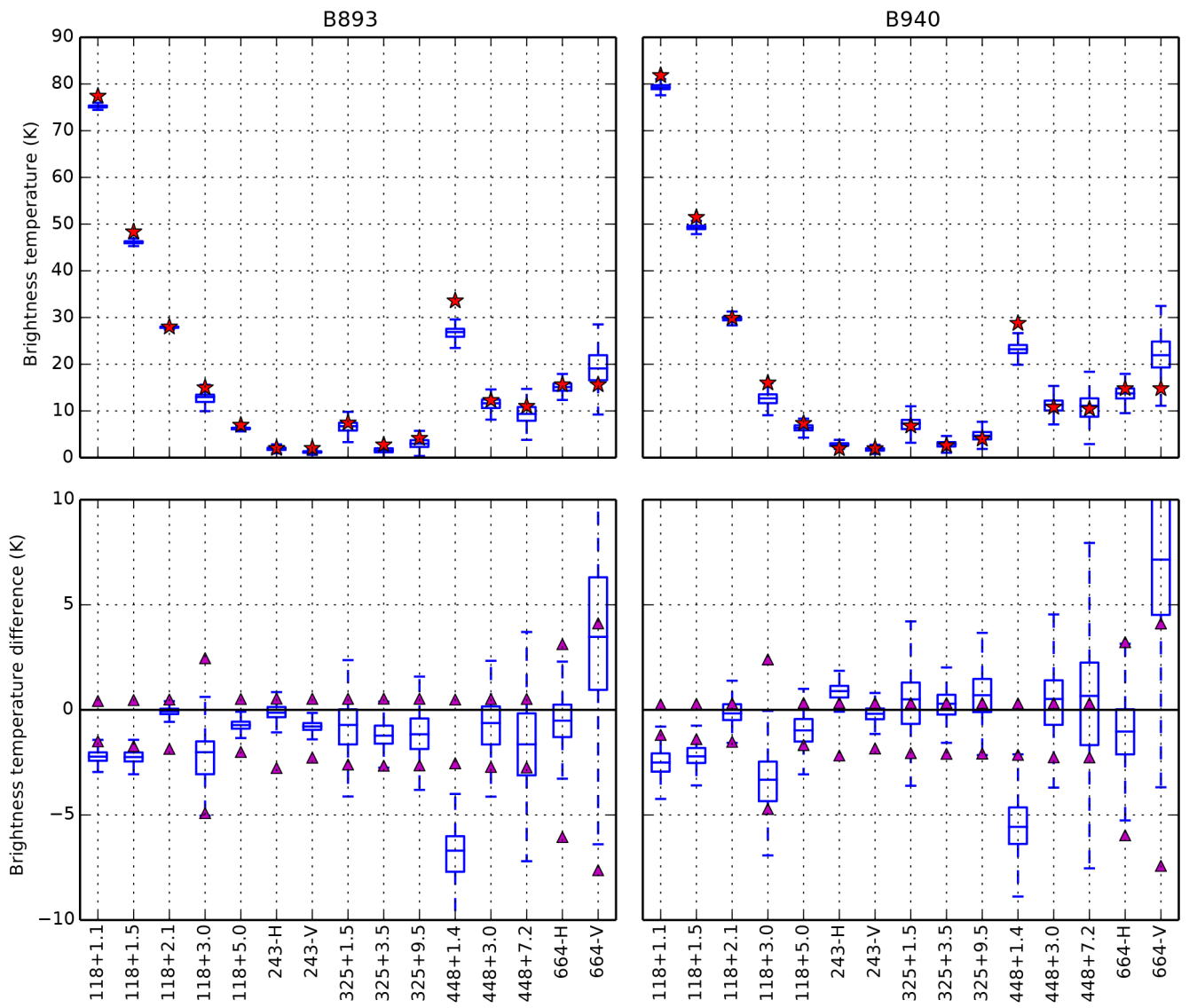

Figure 6. Top: zenith brightness temperatures during straight and level flight above the tropopause. The box and whiskers are the ISMAR measurements, and the stars are simulations. Bottom: difference between measurements and simulations. The triangles represent the estimated maximum bias in the measurements.

\subsection{Receiver linearity}

Departures of the receiver response from the ideal linear response (Eq. 1) lead to errors in calibrated brightness temperatures. Laboratory tests suggest that the $118 \mathrm{GHz}$ and 243 $\mathrm{V}$ receivers have a slightly non-linear response, most likely caused by non-linearity in the diode detectors. A correction for receiver non-linearity has been derived by assuming the detector has a quadratic response:

$V_{\mathrm{det}}=k_{\mathrm{D}} P_{\mathrm{D}}+k_{\mathrm{N}} P_{\mathrm{D}}^{2}$

where $V_{\text {det }}$ is the detector output voltage, $P_{\mathrm{D}}$ is the detector input power, $k_{\mathrm{D}}$ is the linear gain of the detector and $k_{\mathrm{N}}$ parameterises the detector non-linearity. The detector input power is given by

$P_{\mathrm{D}}=k_{\mathrm{PD}}\left(T_{\text {scene, rje }}+T_{\text {sys }}\right)$,

where $k_{\mathrm{PD}}$ is the total receiver gain prior to the detector and $T_{\text {sys }}$ is the system noise temperature.
Substituting Eqs. (12) and (13) into the calibration Eqs. (1) leads to a scene brightness temperature error

$\Delta T_{\text {scene,rje }}=\frac{\epsilon\left(T_{\text {scene, rje }}-T_{\text {hot, rje }}\right)\left(T_{\text {scene, rje }}-T_{\text {cold,rje }}\right)}{1+\epsilon\left(T_{\text {hot, }, \text { je }}+T_{\text {cold, rje }}+2 T_{\text {sys }}\right)}$,

where $\epsilon$ is a parameter describing the detector non-linearity defined by

$\epsilon=\frac{k_{\mathrm{N}} k_{\mathrm{PD}}}{k_{\mathrm{D}}}$.

For measurements of a known scene temperature Eq. (14) can be used to derive $\epsilon$. This has been done using laboratory measurements of a liquid-nitrogen-cooled calibration target. By assuming that $k_{\mathrm{N}} / k_{\mathrm{D}}$ is constant for a given detector and that changes in $k_{\mathrm{PD}}$ are proportional to changes in overall linear gain given by Eq. (2), the value of $\epsilon$ applicable to any scene view can be calculated. Equation (14) is then used to calculate and correct for the non-linearity in each scene measurement. For scene temperatures close to the calibration target temperatures the non-linearity correction is small (typically less than $1 \mathrm{~K}$ for nadir views). However, for very cold 
scenes such as high-altitude zenith views the correction can be as large as $10 \mathrm{~K}$. Attenuators have therefore been added to the 118 - and $243-\mathrm{V}$ receivers prior to the detectors, which reduces the effect of the non-linearity by reducing $k_{\mathrm{PD}}$, at the expense of reducing the dynamic range of the signal. The attenuators were fitted from flight B939 (February 2016) onwards.

\section{Sensitivity}

The ability of ISMAR to distinguish brightness temperature changes caused by clouds or changes in atmospheric profiles depends on the radiometric sensitivity as described by the noise equivalent $\Delta T(\mathrm{NE} \Delta T)$. For a total power radiometer like ISMAR with periodic views of calibration loads the $\mathrm{NE} \Delta T$ depends on a number of factors, including the scene temperature, system noise temperature, receiver bandwidth, scene and calibration view integration time, time-correlated receiver gain fluctuations, calibration averaging parameters and calibration load temperatures (Hersman and Poe, 1981). It is useful to provide estimates of NE $\Delta T$ alongside ISMAR measurements to allow the significance of changes in brightness temperature to be assessed.

Hersman and Poe (1981) derive an expression for NE $\Delta T$ in terms of the scan and calibration parameters and the receiver output voltage power spectral density which gives a worst-case estimate when the scene temperature lies between the calibration load temperatures. Since ISMAR uses an ambient temperature target as the cold calibration load rather than the cold space view typically used by satellite radiometers, it is possible for the scene temperature to be significantly colder than either calibration load, which can lead to larger $\mathrm{NE} \Delta T$ due to the extrapolation of the derived calibration coefficients. It is relatively simple to extend the analysis to cover this case, leading to an expression of the form

$$
\begin{aligned}
& (\mathrm{NE} \Delta \mathrm{T})^{2} \approx \frac{T_{\mathrm{sys}}^{2}}{\tau_{\mathrm{s}} \Delta v}+K^{2} \frac{T_{\mathrm{sys}}^{2}}{\tau_{\mathrm{c}} \Delta v} \sum_{k=1}^{n_{\mathrm{cal}}} w_{\mathrm{hot}, k}^{2} \\
& +(1-K)^{2} \frac{T_{\text {sys }}^{2}}{\tau_{\mathrm{c}} \Delta v} \sum_{k=1}^{n_{\mathrm{cal}}} w_{\text {cold }, k}^{2} \\
& +\frac{1}{G^{2}} \int_{0}^{\infty} S_{g}(f) H\left(f, K, \tau_{\mathrm{s}}, \tau_{\mathrm{c}}, w_{\mathrm{hot}, 1 \ldots n_{\mathrm{cal}}},\right.
\end{aligned}
$$

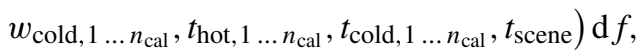

where $f$ is frequency; $\tau_{\mathrm{s}}$ is the scene integration time; $\tau_{\mathrm{c}}$ is the calibration view integration time; $w_{\text {hot }}$ and $w_{\text {cold }}$ are the weightings applied to each of the $n_{\text {cal }}$ calibration views; $t_{\text {hot }}, t_{\text {cold }}$ and $t_{\text {scene }}$ are the times of the calibration and scene views; $S_{g}(f)$ is the non-uniform component of the receiver output voltage power spectral density (which includes contributions from time-correlated gain fluctuations); and $H$ is the calibration processing transfer function, which has a similar form to that given by Hersman and Poe (1981) but includes additional terms and depends on the calibration extrapolation factor $K$ (defined in Eq. 9).

For receiver noise with a uniform power spectral density $S_{g}(f)=0$ (i.e. no time-correlated output fluctuations) the minimum NE $\Delta T$ is obtained by using a uniform weighting of a large number of calibration views. However, in the presence of non-uniform receiver noise $S_{g}(f) \sim f^{-n}$, increasing the time over which the calibration views are averaged increases the contribution from the non-uniform noise component, which can outweigh the reduction in the contribution of the uniform component and give an increase in NE $\Delta T$. Laboratory measurements of $S_{g}(f)$ for the ISMAR receivers show that significant non-uniform noise spectral density affects all channels for frequencies representative of the time taken to complete a single scan cycle. The calibration averaging method must therefore be carefully selected to avoid degrading the sensitivity.

The optimum calibration averaging time and weightings in the presence of time-correlated noise depends on both the form of $S_{g}(f)$ and the value of $K$. However, for ISMAR processing a uniform weighting of all calibration views within a $60 \mathrm{~s}$ window centred on the time of the scene view has been selected. This is simple to implement, gives a relatively constant NE $\Delta T$ for all values of $K$ and does not significantly increase the NE $\Delta T$ above the value that could be obtained by using optimised weightings for each scene view. Table 3 shows the estimated NE $\Delta T$ calculated using Eq. (16) for a typical ISMAR scan pattern for $K=0.5$ and -3.6 . For comparison, the standard deviation of the measured brightness temperature of a liquid-nitrogen-cooled external calibration target over a $60 \mathrm{~s}$ period is also shown. There is close agreement with the calculated NE $\Delta T$ for $K=-3.6$, which is the value applicable to these measurements.

\section{Flight performance}

ISMAR has flown on 17 flights during three measurement campaigns: STICCS (Sub-millimetre Trials In Clear and Cloudy Skies) based in Prestwick (UK) in November and December 2014, COSMICS (Cold-air Outbreak and Submillimetre Ice Cloud Studies) based in Prestwick and Keflavik (Iceland) during March 2015 and Winter Experiment 2016 (WINTEX-16) based in Cranfield (UK) during February and March 2016. The locations and times of the campaigns were chosen to maximise the opportunities to fly above cirrus cloud given the maximum altitude of the FAAM aircraft of $35000 \mathrm{ft}$ (approximately $11 \mathrm{~km}$ ). In this section the in-flight performance of ISMAR is assessed by comparing high-altitude zenith views in clear skies with radiativetransfer simulations.

High-altitude zenith views are selected for this comparison because above the tropopause the atmospheric absorption and emission due to water vapour are very small. Away 
Table 3. NE $\Delta T$ estimates for ISMAR channels.

\begin{tabular}{lrrr}
\hline Channel & Calculated NE $\Delta T(\mathrm{~K})$ & Calculated NE $\Delta T(\mathrm{~K})$ & Measured NE $\Delta T(\mathrm{~K})$ \\
& $K=0.5$ & $K=-3.6$ & LN2 target $(K \approx-3.6)$ \\
\hline $118 \pm 1.1$ & 0.2 & 0.3 & 0.4 \\
$118 \pm 1.5$ & 0.2 & 0.3 & 0.4 \\
$118 \pm 2.1$ & 0.2 & 0.3 & 0.3 \\
$118 \pm 3.0$ & 0.2 & 0.4 & 0.3 \\
$118 \pm 5.0$ & 0.2 & 0.3 & 0.3 \\
$243-\mathrm{H}$ & 0.3 & 0.5 & 0.4 \\
$243-\mathrm{V}$ & 0.5 & 0.6 & 0.3 \\
$325 \pm 1.5$ & 1.1 & 1.8 & 1.6 \\
$325 \pm 3.5$ & 0.3 & 0.5 & 0.7 \\
$325 \pm 9.5$ & 0.8 & 1.2 & 1.1 \\
$448 \pm 1.4$ & 0.9 & 1.5 & 1.1 \\
$448 \pm 3.0$ & 1.3 & 2.0 & 1.6 \\
$448 \pm 7.2$ & 1.9 & 2.9 & 2.8 \\
$664-\mathrm{H}$ & 0.9 & 1.4 & 1.3 \\
$664-\mathrm{V}$ & 2.7 & 3.9 & 3.3 \\
\hline
\end{tabular}

from oxygen absorption lines the atmospheric contribution to the zenith brightness temperatures is therefore low, and the measurements are dominated by the cold space background. Due to the small atmospheric contribution the errors in radiative-transfer simulations are expected to be small, in contrast to nadir views where uncertainties in atmospheric profiles, spectroscopy and surface properties can make a significant difference to simulated brightness temperatures. Cold zenith scenes also represent a challenging measurement as they require significant extrapolation from the calibration target temperatures. The top row of Fig. 6 shows the zenith measurements made during two flights (B893 and B940) where the aircraft was in straight and level flight above the tropopause. Also shown are radiative-transfer simulations performed using the Atmospheric Radiative Transfer Simulator (ARTS) (Eriksson et al., 2011). Absorption and emission due to water vapour and oxygen were calculated using the complete absorption models of Rosenkranz (1998, 1993), and ozone lines were taken from the high-resolution transmission molecular absorption database (HITRAN; Rothman et al., 2013). The profiles of temperature and water vapour were taken from short-term Met Office forecast models valid at the time of the measurements, and a monthly climatology was used for the ozone profile. Ozone absorption and emission make a contribution to zenith brightness temperatures at frequencies of $325 \mathrm{GHz}$ and above.

The bottom row of Fig. 6 shows the difference between the measured and simulated brightness temperatures. The maximum estimated bias in the measurements due to calibration target temperature bias and standing-wave effects are also indicated. The majority of the measurements are consistent with the simulations, with small biases even at these very low scene temperatures. The main differences occur for the $118 \pm 1.1,118 \pm 1.5$ and $448 \pm 1.4 \mathrm{GHz}$ channels which are close to the centre of the gaseous absorption lines and are most sensitive to errors in the input profiles of temperature and humidity. Larger discrepancies are also seen for the channels where standing-wave effects increase the calibration uncertainty.

\section{Conclusions}

The ISMAR radiometer has been developed as an airborne demonstrator for ICI and has flown on the FAAM BAe-146 during a number of measurement campaigns. It contains heterodyne receivers operating at frequencies between 118 and $664 \mathrm{GHz}$ which are sensitive to scattering by cloud ice particles, and has a flexible scanning geometry allowing both upward and downward views.

For downward-looking views from high altitude, representative of the satellite viewing geometry, the majority of the channels have a bias less than $\pm 1 \mathrm{~K}$. For most channels the biggest source of bias is thermal gradients in the heated calibration target. Standing waves due to coherent backscatter from the calibration targets are the dominant source of bias at $118 \pm 3.0$ and $664 \mathrm{GHz}$. It is hoped that biases due to thermal gradients can be reduced in future by improved characterisation of the target temperatures. The NE $\Delta T$ for downward views in most channels is also less than $1 \mathrm{~K}$, and it is less than $2 \mathrm{~K}$ for all channels other than $664-\mathrm{V}$. The presence of time-correlated noise in the receiver output prevents the NE $\Delta T$ from being reduced by averaging a larger number of calibration views.

Zenith brightness temperatures measured above the tropopause have been compared with radiative-transfer simulations. The agreement is generally very good, and the differences are mostly consistent with the expected measurement uncertainties. 
In future ISMAR will be used to validate radiative-transfer models at submillimetre wavelengths for both clear and cloudy conditions, and to test retrieval algorithms for cloud ice properties. It can also be used for surface studies and postlaunch calibration/validation for ICI. Additional receivers at 874.4 GHz, which will give greater sensitivity to low ice water path and small ice particles, are currently being developed and will be integrated into ISMAR when they are available.

\section{Data availability}

The data used in the comparison between aircraft measurements and simulations in Sect. 6 are available in the supplement.

Competing interests. The authors declare that they have no conflict of interest.

\section{The Supplement related to this article is available online at doi:10.5194/amt-10-477-2017-supplement.}

Acknowledgements. ISMAR has been jointly funded by the Met Office and the European Space Agency under the "Cloud and Precipitation Airborne Radiometer" project. The authors would also like to thank the crew and personnel involved in the STICCS, COSMICS and WINTEX-16 campaigns. The BAe-146 research aircraft is operated by Airtask and Avalon and managed by the Facility for Airborne Atmospheric Measurements (FAAM), which is jointly funded by the Met Office and Natural Environment Research Council (NERC).

Edited by: I. Moradi

Reviewed by: two anonymous referees

\section{References}

Afsar, M. N.: Precision Dielectric Measurements of Nonpolar Polymers in the Millimeter Wavelength Range, IEEE T. Microw. Theory, 33, 1410-1415, doi:10.1109/TMTT.1985.1133232, 1985.

Baran, A. J.: A new application of a multifrequency submillimeter radiometer in determining the microphysical and macrophysical properties of volcanic plumes: A sensitivity study, J. Geophys. Res.-Atmos., 117, D00U18, doi:10.1029/2011JD016781, 2012.

Bizzari, B., Bizzarri, B., Amato, U., Bates, J., Benesch, W., Buehler, S., Capaldo, M., Cervino, M., Cuomo, V., Leonibus, L., Desbois, M., Dietrich, S., Evans, F., Eymard, L., Gasiewski, A., Gustafsson, N., Heygster, G., Klein, M., Kunzi, K., Levizzani, V., Liberti, G. L., Lopez-Baeza, E., Menzel, P., Miao, J., Mugnai, A., Pagano, P., Pailleux, J., Pardo, J., Porcu, F., Prigent, C., Prodi, F., Rizzi, R., Rochard, G., Roesli, H. P. Serio, C., Smith, W., Speranza, A., Staelin, D., Sutera, A., Tsou, J.-J., Velden, C., and Visconti, G.: GOMAS - Geostationary Observatory for Microwave
Atmospheric Sounding, submitted to ESA in response to the call for ideas for the Next Earth Explorer Core Missions, 2005.

Buehler, S. A., Jiménez, C., Evans, K. F., Eriksson, P., Rydberg, B., Heymsfield, A. J., Stubenrauch, C. J., Lohmann, U., Emde, C., John, V. O., Sreerekha, T. R., and Davis, C. P.: A concept for a satellite mission to measure cloud ice water path, ice particle size, and cloud altitude, Q. J. Roy. Meteor. Soc., 133, 109-128, doi:10.1002/qj.143, 2007.

Eriksson, P., Buehler, S., Davis, C., Emde, C., and Lemke, O.: ARTS, the atmospheric radiative transfer simulator, version 2, J. Quant. Spectrosc. Ra., 112, 1551-1558, doi:10.1016/j.jqsrt.2011.03.001, 2011.

Evans, K. and Stephens, G.: Microwave radiative transfer through clouds composed of realistically shaped ice crystals. Part II: remote sensing of ice clouds, J. Atmos. Sci., 52, 2058-2072, doi:10.1175/1520-0469(1995)052<2058:MRTTCC>2.0.CO;2, 1995.

Evans, K. F., Walter, S. J., Heymsfield, A. J., and Deeter, M. N.: Modeling of submillimeter passive remote sensing of cirrus clouds, J. Appl. Meteorol., 37, 184-205, doi:10.1175/15200450(1998)037<0184:MOSPRS>2.0.CO;2, 1998.

Evans, K. F., Wang, J. R., Racette, P. E., Heymsfield, G., and Li, L.: Ice Cloud Retrievals and Analysis with the Compact Scanning Submillimeter Imaging Radiometer and the Cloud Radar System during CRYSTAL FACE, J. Appl. Meteorol., 44, 839-859, doi:10.1175/JAM2250.1, 2005.

Evans, K. F., Wang, J. R., O'C Starr, D., Heymsfield, G., Li, L., Tian, L., Lawson, R. P., Heymsfield, A. J., and Bansemer, A.: Ice hydrometeor profile retrieval algorithm for high-frequency microwave radiometers: application to the CoSSIR instrument during TC4, Atmos. Meas. Tech., 5, 2277-2306, doi:10.5194/amt5-2277-2012, 2012.

Han, Y. and Westwater, E. R.: Analysis and improvement of tipping calibration for ground-based microwave radiometers, IEEE T. Geosci. Remote Sens., 38, 1260-1276, doi:10.1109/36.843018, 2000.

Hejase, J. A., Paladhi, P. R., and Chahal, P. P.: Terahertz Characterization of Dielectric Substrates for Component Design and Nondestructive Evaluation of Packages, IEEE T. Compon. Pack. T., 1, 1685-1694, doi:10.1109/TCPMT.2011.2163632, 2011.

Hersman, M. S. and Poe, G.: Sensitivity of the total power radiometer with periodic absolute calibration, IEEE T. Microw. Theory, 29, 32-40, doi:10.1109/TMTT.1981.1130283, 1981.

Hewison, T.: The design of Deimos: a microwave radiometer with channels at $23.8 \mathrm{GHz}$ and $50.3 \mathrm{GHz}$ for the UK Met. Research Flight C-130 aircraft, in: International Geoscience and Remote Sensing Symposium 'Quantitative Remote Sensing for Science and Applications', Firenze, Italy, vol. 3, 2261-2263, doi:10.1109/IGARSS.1995.524165, 1995.

Jiménez, C., Buehler, S., Rydberg, B., Eriksson, P., and Evans, K.: Performance simulations for a submillimetre-wave satellite instrument to measure cloud ice, Q. J. Roy. Meteor. Soc., 133, 129149, doi:10.1002/qj.134, 2007.

Jin, Y.-S., Kim, G.-J., and Jeon, S.-G.: Terahertz dielectric properties of polymers, J. Korean Phys. Soc., 49, 513-517, 2006.

Jones, D.: Validation of scattering microwave radiative transfer models using an aircraft radiometer and ground-based radar, Ph.D thesis, University of Reading, 1995. 
Kangas, V., D’Addio, S., Betto, M., Barre, H., Loiselet, M., and Mason, G.: Metop Second Generation microwave sounding and microwave imaging missions, in: Proceedings of the 2012 EUMETSAT Meteorological Satellite Conference, Sopot, Poland, 3-7 September, 2012.

Lee, C., Evans, K. F., Nolt, I. G., Smith, W. L., and Vanek, M. D.: Far-infrared remote sensing measurements of cirrus clouds during AFWEX, Proc. SPIE 4539, Remote Sensing of Clouds and the Atmosphere VI, 26, 4 February 2002, doi:10.1117/12.454461, 2002.

McGrath, A. and Hewison, T.: Measuring the accuracy of MARSS-an airborne microwave radiometer, J. Atmos. Ocean. Technol., 18, 2003-2012, doi:10.1175/15200426(2001)018<2003:MTAOMA>2.0.CO;2, 2001.

Murk, A., Duric, A., and Patt, F.: Characterization of ALMA calibration targets, in: Proc. 19th International Symposium on Space Terahertz Technology, Groningen, 28-30 April 2008, 530-533, 2008.

Murtagh, D., Frisk, U., Merino, F., Ridal, M., Jonsson, A., Stegman, J., Witt, G., Eriksson, P., Jiménez, C., Megie, G., de la Noë, J., Ricaud, P., Baron, P., Pardo, J. R., Hauchcorne, A., Llewellyn, E. J., Degenstein, D. A., Gattinger, R. L., Lloyd, N. D., Evans, W. F., McDade, I. C., Haley, C. S., Sioris, C., von Savigny, C., Solheim, B. H., McConnell, J. C., Strong, K., Richardson, E. H., Leppelmeier, G. W., Kyrölä, E., Auvinen, H., and Oikarinen, L.: An overview of the Odin atmospheric mission, Canad. J. Phys., 80, 309-319, doi:10.1139/p01-157, 2002.

Rosenkranz, P. W.: Absorption of microwaves by atmospheric gases, in: Atmospheric remote sensing by microwave radiometry, edited by: Janssen, M. A., 37-90, John Wiley \& Sons, Inc., 1993.

Rosenkranz, P. W.: Water vapor microwave continuum absorption: A comparison of measurements and models, Radio Sci., 33, 919928, doi:10.1029/98RS01182, 1998.

Rothman, L., Gordon, I., Babikov, Y., Barbe, A., Benner, D. C., Bernath, P., Birk, M., Bizzocchi, L., Boudon, V., Brown, L., Campargue, A., Chance, K., Cohen, E., Coudert, L., Devi, V., Drouin, B., Fayt, A., Flaud, J.-M., Gamache, R., Harrison, J., Hartmann, J.-M., Hill, C., Hodges, J., Jacquemart, D., Jolly, A., Lamouroux, J., Roy, R. L., Li, G., Long, D., Lyulin, O., Mackie, C., Massie, S., Mikhailenko, S., Müller, H., Naumenko, O., Nikitin, A., Orphal, J., Perevalov, V., Perrin, A., Polovtseva, E., Richard, C., Smith, M., Starikova, E., Sung, K., Tashkun, S., Tennyson, J., Toon, G., Tyuterev, V., and Wagner, G.: The HITRAN2012 molecular spectroscopic database, J. Quant. Spectrosc. Ra., 130, 4-50, doi:10.1016/j.jqsrt.2013.07.002, 2013.
Staelin, D., Gasiewski, A., Kerekes, J., Shields, M., and Solman III, F.: Concept proposal for a Geostationary Microwave (GEM) Observatory, prepared for the NASA/NOAA Advanced Geostationary Sensor (AGS) Program, MIT, Lexington, MA, USA, p. 23, 1998.

Ulaby, F. T., Moore, R. K., and Fung, A. K.: Microwave remote sensing active and passive volume 1, Addison-Wesley, p. 247, 1981.

Waliser, D. E.. Li, J.-L. F.. Woods, C. P., Austin, R. T. Bacmeister, J., Chern, J., Del Genio, A., Jiang, J. H., Kuang, Z., Meng, H., Minnis, P., Platnick, S., Rossow, W. B., Stephens, G. L., SunMack, S., Tao, W.-K., Tompkins, A. M., Vane, D. G., Walker, C., and Wu, D.: Cloud ice: A climate model challenge with signs and expectations of progress, J. Geophys.-Res., 114, D00A21, doi:10.1029/2008JD010015, 2009.

Wang, J. R., Liu, G., Spinhirne, J. D., Racette, P., and Hart, W. D.: Observations and retrievals of cirrus cloud parameters using multichannel millimeter-wave radiometric measurements, J. Geophys. Res.-Atmos., 106, 15251-15263, doi:10.1029/2000JD900262, 2001.

Waters, J. W., Froidevaux, L., Harwood, R. S., Jarnot, R. F., Pickett, H. M., Read, W. G., Siegel, P. H., Cofield, R. E., Filipiak, M. J., Flower, D. A., Holden, J. R., Lau, G. K., Livesey, N. J., Manney, G. L., Pumphrey, H. C., Santee, M. L., Wu, D. L., Cuddy, D. T., Lay, R. R., Loo, M. S., Perun, V. S., Schwartz, M. J., Stek, P. C., Thurstans, R. P., Boyles, M. A., Chandra, K. M., Chavez, M. C., Chen, G.-S., Chudasama, B. V., Dodge, R., Fuller, R. A., Girard, M. A., Jiang, J. H., Jiang, Y., Knosp, B. W., LaBelle, R. C., Lam, J. C., Lee, K. A., Miller, D., Oswald, J. E., Patel, N. C., Pukala, D. M., Quintero, O., Scaff, D. M., Snyder, W. V., Tope, M. C., Wagner, P. A., and Walch, M. J.: The Earth observing system microwave limb sounder (EOS MLS) on the aura Satellite, IEEE T. Geosci. Remote Sens., 44, 1075-1092, doi:10.1109/TGRS.2006.873771, 2006. 